\title{
El Constitucionalismo más allá del Estado de Luigi Ferrajoli ante la Pandemia por SARS-CoV-2
}

\section{Constitutionalism beyond the State of Luigi Ferrajoli in the face of the SARS-CoV-2 Pandemic}

HiRAm RaÚl PiÑa Libien ${ }^{1}$ ENRIQUE URIBE ARZATE ${ }^{2}$ JORGE OLVERA GARCÍA

$0^{\circ}$ IUS Comitiãlis / Año 3, Número 6 / julio - diciembre 2020 / pp. 60-85 / ISSN: 2594-1356 Recepción: 4 de mayo del 2020 / Aceptación: 15 de agosto de 2020

Resumen: La pandemia generada por la propagación del virus SARS-CoV-2 demandó que los gobiernos instrumentaran una serie de medidas orientadas a la protección de la salud de las personas, así como políticas fiscales, monetarias y laborales para estimular la economía y el empleo. En este trabajo, a través del método de derecho comparado, se efectúa un análisis descriptivo de las medidas adoptadas en China, Italia, España, Francia, Alemania, Estados Unidos de Norteamérica y México, con el objeto de calibrar si responden a las innovaciones que el Constitucionalismo más allá del Estado de Luigi Ferrajoli busca introducir en el paradigma constitucional.

Palabras clave: Coronavirus, COVID-19, Salud, Constitucionalismo, Pandemia, SARS-CoV-2.

Abstract: The pandemic generated by the spread of the SARS-CoV-2 virus demanded that governments implement a series of measures aimed at protecting people's health, as well as fiscal, monetary and labor policies to stimulate the economy and employment. In this work, through the comparative law method, a descriptive analysis of those adopted in China, Italy, Spain, France, Germany, United States of America and Mexico is carried out, in order to gauge whether they respond to the innovations that Constitutionalism beyond the State of Luigi Ferrajoli seeks to introduce into the constitutional paradigm.

Key words: Coronavirus, COVID-19, Health, Constitutionalism, Pandemic, SARS-CoV-2.

http://orcid.org/0000-0002-5745-6880. / Correo electrónico: hrpl@hotmail.com

${ }^{1}$ Doctor en Derecho, Profesor-investigador de tiempo completo en la Facultad de Derecho de la Universidad Autónoma del Estado de México, México. Perfil PRODEP-SEP.

https://orcid.org/0000-0003-2381-232X. / Correo electrónico: vercingtx@hotmail.com

${ }^{2}$ Doctor en Derecho, Profesor-investigador de tiempo completo en la Facultad de Derecho de la Universidad Autónoma del Estado de México, México. Miembro del Sistema Nacional de Investigadores Nivel II.

https://orcid.org/0000-0002-2607-8987. / Correo electrónico: jorgeolvera62@hotmail.com

${ }^{3}$ Doctor en Derecho, Presidente de la Comisión de Derechos Humanos del Estado de México, México. 
HiRAm RaÚl PiÑa Libien / http://orcid.org/0000-0002-5745-6880. / Correo electrónico: hrpl@hotmail.com ENRIQUE URIBE ARZATE / https://orcid.org/0000-0003-2381-232X. / Correo electrónico: vercingtx@hotmail.com Jorge Olvera García / https://orcid.org/0000-0002-2607-8987. / Correo electrónico: jorgeolvera62@hotmail.com

\section{INTRODUCCIÓN}

Con el objeto de conmemorar el centenario de la Constitución Política de los Estados Unidos Mexicanos, el Consejo de Salubridad General editó un texto cuya característica principal es el análisis prospectivo y especulativo de los aspectos sociales, demográficos, políticos y económicos de la salud en México. En el capítulo escrito por Enrique Ruelas y Antonio Alonso (2010) se señala que hacia el año 2020 se introduce en México un nuevo virus de alta letalidad, para el que no existe cura conocida (a pesar de las restricciones en su transmisión), se estima que debido a su causa fallece cerca de medio millón de personas. Sin embargo, luego de varios meses, las medidas preventivas introducidas permiten controlar la epidemia (383).

Durante el primer cuatrimestre del año 2020 dicho escenario abandono el contexto de la prospectiva y la especulación, pues el 30 de enero de 2020, en atención a la recomendación del Comité de Seguridad, la Organización Mundial de la Salud (OMS) declaró, emergencia de salud pública de importancia internacional, luego del brote de una nueva variante de coronavirus, cuyos iniciales casos fueron identificados durante diciembre de 2019 en la ciudad de Wuhan, China.

La rápida propagación del virus SARS-CoV-2 y la enfermedad conocida como 2019-nCoV ha traído consigo una diversidad de retos para todas las estructuras de la sociedad según la OMS y el Comité Internacional de Taxonomía de Virus (M. Palacios Cruz, et. al.: 2020). Las medidas de prevención, contención y mitigación emprendidas han puesto a prueba, no solo a los sistemas de salud, también a las estructuras económicas, políticas y sociales que se enfrentan a un reto de mayor magnitud, como fueron en su momento, la depresión económica de 1929, la segunda guerra mundial o la crisis financiera mundial de 2008.

No obstante, el surgimiento de una nueva variante de coronavirus ha representado también un paradigma para las actividades de investigación científica en la búsqueda y desarrollo de una vacuna. A la vez, ha significado que las estructuras de gobierno pongan en funcionamiento medidas que jurídicamente permitan afrontar una enfermedad que a nivel mundial (desde el 15 de abril de 2020) ha sido detectada a 2,134,465 personas, propiciando la muerte de 142,148 de ellas (Johns Hopkins University, 2020). El objeto de tales medidas no ha sido solamente prevenir el riesgo de contagio de la enfermedad por coronavirus, a la par, se espera establecer mecanismos jurídicos orientados a salvaguardar el derecho humano a la salud.

El presente trabajo se desarrolla usando como referencia el Constitucionalismo más allá del Estado de Luigi Ferrajoli (2018), nos ocupamos del análisis descriptivo de las medidas de contención y mitigación desde una perspectiva del derecho comparado, tomando para ello, como puntos geográficos de referencia, a China, país en el cual tuvo origen la noticia del brote; Italia, España, Francia y Alemania, naciones 
que presentan cifras superiores a cien mil casos confirmados en cada uno; Estados Unidos de Norteamérica por ocupar el primer lugar de contagios a nivel mundial, al contabilizar la confirmación de más de trescientos mil casos, y finalmente, México por la pertenencia nacional de los autores. Igualmente, efectuamos una revisión de los posicionamientos político-jurídicos de la Organización de las Naciones Unidas (ONU) y de la Comisión Interamericana de Derechos Humanos (CIDH).

A partir de tales contextos buscamos calibrar los alcances de las medidas jurídicas tomadas en cada soberanía a la luz de la hipótesis teórica propuesta por Luigi Ferrajoli (2020), quien ha sostenido que la única manera realista de afrontar problemas globales de tal envergadura es, a través de un Constitucionalismo más allá del Estado, de una Constitución de la Tierra.

\section{EL CONSTITUCIONALISMO MÁS ALLÁ DEL ESTADO DE LUIGI FERRAJOLI: RESPUESTA EMERGENTE PARA HACER FRENTE A UNA PANDEMIA}

Con motivo de la inauguración de la Escuela Constituyente de la Tierra, el 21 de febrero de 2020 en el Salón Borromini de la Biblioteca Vallicelliana, en Roma, Italia, el profesor emérito de filosofía del derecho en la Universidad de Roma, Luigi Ferrajoli, dictó la conferencia intitulada ¿Por qué una Constitución de la Tierra? (Radio Radicale, 2020). En esa oportunidad, basado en su idea de un Constitucionalismo más allá del Estado,expuso una propuesta que calificó como una utopía, una propuesta poco realista e inalcanzable: la Constitución de la Tierra.

Con la intención de crear una escuela basada en la idea de una "Tierra Constituyente", cuya finalidad es inducir a la reflexión colectiva desde una perspectiva que garantice los derechos fundamentales de los ciudadanos, ante los desafíos y catástrofes mundiales, se erige un movimiento destinado a crear un constitucionalismo supranacional, que llene el vacío de derecho público, producido por la asimetría entre el carácter global de los poderes salvajes de hoy así como del carácter predominantemente local de la política y el derecho.

Tras advertir la inexistencia de un pueblo global homogéneo, considera que existen problemas globales que no forman parte de la agenda política de los gobiernos nacionales, que se traducen en temas de referencia humanitaria, tales como: las armas nucleares; el capitalismo voraz y depredador; la existencia de un sistema industrial ecológicamente insostenible, la devastación del planeta y los desastres ecológicos; el crecimiento de las desigualdades, la pobreza y el racismo; las guerras, y desde luego, las catástrofes humanitarias, por lo que plantea la necesidad y urgencia de ampliar el paradigma constitucional nacional mediante su proyección a nivel internacional.

A este par de cuestiones, añadió la existencia de estados soberanos con políticas inadecuadas, que, por inercia o silencio, son inoperantes para hacer frente a los 
HiRAM RAÚl PiÑA LiBIEn / http://orcid.org/0000-0002-5745-6880. / Correo electrónico: hrpl@hotmail.com ENRIQUE URIBE ARZATE / https://orcid.org/0000-0003-2381-232X. / Correo electrónico: vercingtx@hotmail.com Jorge Olvera García / https://orcid.org/0000-0002-2607-8987. / Correo electrónico: jorgeolvera62@hotmail.com

problemas globales, se trata pues, de estados que, por una parte, acusan una marcada subordinación a la economía generada por la corrupción, los conflictos de intereses y las presiones de cabildeo; y por otra, se encuentran limitados a tiempos cortos y espacios reducidos.

Estos dos últimos aspectos, determinan que los gobiernos estatales -en el tiempo- se encuentren concentrados únicamente en las competencias electorales y las encuestas, y -en el espacio- no puedan ver más allá de su territorio. Por ello, considera Ferrajoli que, las democracias modernas se encuentran enfermas de amnesia, miopía e irresponsabilidad, puesto que eliminan el pasado y no se hacen cargo del futuro, que no ven más allá de los tiempos que marcan los calendarios y procesos electorales, restringiendo su actuación a sus fronteras nacionales.

Para el filósofo italiano, la necesidad de desarrollar un constitucionalismo más allá del estado obedece al propósito de introducir dos innovaciones en el paradigma constitucional.

La primera, es la urgencia de contar con instituciones de garantía de los derechos humanos, en donde la Constitución de la Tierra, como construcción teórica, tiene como base embrionaria la Carta de las Naciones Unidas de 1945 y los diversos instrumentos internacionales existentes sobre derechos humanos, en los que se inscriben los principios de paz, igualdad y de los derechos humanos; pero a la vez, del reconocimiento de que, a nivel global, los derechos sociales fundamentales (salud, educación, subsistencia, bienes comunes contra la devastación ambiental y la inexistencia de garantías jurisdiccionales, a partir del control de la constitucionalidad y la convencionalidad) se vuelven ineficaces en virtud de que no cuentan con garantías específicas para su conservación.

La segunda innovación parte de la premisa de que la Constitución de la Tierra no diverge con la necesaria democratización de la Organización de las Naciones Unidas, pero va más allá, plantea la necesidad de introducir técnicas, funciones e instituciones adecuadas de garantía de los derechos fundamentales. Esto implica, por ejemplo, la financiación adecuada de instituciones de garantía global como la Organización Mundial de la Salud, la Organización de las Naciones Unidas para la Alimentación y la Agricultura, la Organización de las Naciones Unidas para la Educación, la Ciencia y la Cultura.

Sin embargo, el objetivo va más allá, pues en la búsqueda de expandir el paradigma constitucional de lo estrictamente estatal, la Constitución de la Tierra pretende dirigirse al establecimiento de: a) un constitucionalismo de derecho internacional o supranacional que este a la altura de los poderes económicos y políticos mundiales; b) paralelamente a la vigente constitucionalidad pública, introducir una constitucionalidad regida por el derecho privado, mediante un sistema adecuado de reglas y garantías contra los poderes salvajes actuales de los mercados; y c) a la par del constitucionalismo de los derechos fundamentales, incorporar un constitucionalismo de los bienes fundamentales, a través de la implementación de garantías destinadas a preservar y garantizar el acceso de todos al disfrute de bienes vitales como los bienes comunes, la 
nutrición básica y los medicamentos.

En suma, la nueva escuela busca reflexionar sobre determinados problemas que enfrenta la humanidad, tales como las catástrofes ecológicas; las guerras nucleares, la producción y multiplicación de armas; así como el hambre y las enfermedades no tratadas.

Es precisamente en este último punto, el caso de las enfermedades no tratadas, y agregaríamos, aquellas que emergen del contagio viral global como el SARS-CoV-2, que adquiere sentido comprender los alcances de las medidas implementadas desde las soberanías para afrontar una pandemia que ha gestado un estado de zozobra mundial ante la implementación de políticas de distanciamiento y confinamiento social, sustentadas en la determinación de que la pandemia debe ser tratada con el carácter de emergencia de salud pública de interés internacional, es decir, como un trastorno público, circunstancia que ha desembocado en la activación de medidas y mecanismos extraordinarios que permitan afrontar no solamente la crisis sanitaria, sino también, las de carácter económico, social y político que ha traído consigo.

\section{MEDIDAS DE CONTENCIÓN Y MITIGACIÓN DEL VIRUS SARS-COV-2 DESDE UNA PERSPECTIVA DE DERECHO COMPARADO}

Tal como se anticipó, se efectuará un análisis descriptivo de las medidas de contención y mitigación que diversos países implementaron para hacer frente a la crisis sanitaria mundial derivada de la propagación del virus SARS-CoV-2, tomando como punto de referencia los instrumentos legales que para tales efectos se han emitido en cada geografía, y a partir de ello, calibrarlas a la luz de la hipótesis teórica propuesta por Luigi Ferrajoli.

\section{A. China}

En la reunión ejecutiva del Consejo de Estado presidida por el primer ministro Li Keqiang el 5 de febrero de 2020, se tomaron decisiones a fin de garantizar el suministro de equipos de atención médica y elementos esenciales diarios, pero también, con el propósito introducir una serie de políticas fiscales y financieras para la prevención de la epidemia y las industrias relacionadas.

Derivado de dicha reunión, se ordenó a los gobiernos locales asumir la responsabilidad de asegurar el abastecimiento de las necesidades diarias; impulsar la producción de verduras, aves y ganado; alentar a las empresas de forraje, sacrificio y procesamiento, así como reiniciar la producción y suministro de carne, huevos y leche.

Las medidas temporales implementadas en China para combatir el nuevo brote de coronavirus, tomadas a partir del 1 de enero de 2020, implicaron estímulos a 
la economía y el empleo mediante una política fiscal de apoyo a empresas involucradas en suministros médicos, transporte y suministros diarios (The State Council, 2020a), medidas fiscales integrales para empresas, particulares y organizaciones sociales (State Taxation Administration, 2020) medidas financieras para ayudar a la pequeña y mediana empresa (PyME) (The State Council, 2020b), apoyo a los gobiernos locales para garantizar el sustento de las personas (The State Council, 2020c), estabilización del comercio exterior y la inversión (The State Council, 2020d).

No obstante, la política fiscal se acompañó de una serie de medidas de política monetaria, que entre otros rubros ha tenido como propósito aumentar la inversión crediticia para apoyar la economía, mantener suficiente liquidez y promover el crecimiento del crédito monetario (Gobierno Popular Central de la República Popular de China, 2020a), subsidio financiero para préstamos corporativos; aumentar el apoyo a los intereses con descuento en préstamos de garantía empresarial; optimizar los servicios de garantía financiera para las empresas afectadas (Gobierno Popular Central de la República Popular de China, 2020b); apoyar la reanudación de la producción; innovar servicios financieros a través de tecnologías; cumplir con la responsabilidad social y mejorar la calidad de los servicios de supervisión financiera (Gobierno Popular Central de la República Popular de China, 2020c); y el aplazamiento temporal del reembolso del principal e intereses de los préstamos de las PyME hasta el 30 de junio, con acuerdos adicionales de extensión para las empresas que necesitan un largo período de recuperación y tienen buenas perspectivas de crecimiento (China Banking and Insurance Regulatory Comission, 2020).

Otro aspecto considerable ha sido la política de apoyo a la empresa, el empleo y los ingresos, misma que ha demandado mayor uso de plataformas en línea para servicios de seguridad social (Ministry of Human Resources and Social Security of the People's Republic of China, 2020a), elegibilidad para beneficios por lesiones para el personal que contrajo COVID-19 en el trabajo (Ministry of Human Resources and Social Security of the People's Republic of China, 2020b), reducción de la contribución de los empleadores a los sistemas de seguridad social (Ministry of Human Resources and Social Security of the People's Republic of China, 2020c), mayor reserva de asignación interprovincial para apoyar mejor a las regiones de bajos ingresos (Gobierno Popular Central de la República Popular de China, 2020d), reembolso de consultas en línea para enfermedades crónicas y comunes (National Healthcare Security Administration, 2020), asistencia social de desempleo de hasta 6 meses para los desempleados que no son elegibles para los beneficios del seguro social de desempleo, así como mayor asistencia social a familias en dificultades (Gobierno Popular Central de la República Popular de China, 2020e).

A la par de la introducción de medidas fiscales y monetarias, se estableció una política de retención de los empleos y protección a los trabajadores, orientada fundamentalmente a la promoción de la contratación en línea, la subvención de formación profesional, la educación gratuita a distancia y el reembolso de las tasas sindicales y las tasas de afiliación de las organizaciones de empleadores para PyME (Ministry of Human Resources and Social Security of the People's Republic of China, 2020d), así como la adopción de medidas para facilitar el empleo, apoyar el emprendimiento, 
contratar graduados universitarios científicos, ampliar los préstamos para nuevas empresas y apoyar las economías de la plataforma para impulsar la economía digital y crear nuevos empleos (The State Council, 2020e).

No menos importante ha sido la política para prevenir la discriminación y la exclusión por motivo de sospecha o infección por COVID-19. Dicha política incluye la protección de la salud física y psicológica, prevención de contagio, remuneración favorable, garantizar el equilibrio entre el trabajo y la familia, así como prevenir la violencia hacia el personal de salud.

\section{B. Italia}

Tomando en consideración la declaratoria de emergencia de salud pública de importancia internacional, emitida por la OMS, y a fin de garantizar un nivel adecuado de protección de la salud, el Ministro de Salud de Italia, instruyó la instauración de medidas profilácticas contra el nuevo coronavirus, consistentes en la prohibición del tráfico aéreo proveniente de China (Gazzetta Ufficiale della Repubblica Italiana, 2020a).

Posteriormente, el Consejo de Ministros de Italia resolvió que, a partir del 31 de enero de 2020 y por un periodo de 6 meses, se declaraba estado nacional de emergencia como consecuencia del riesgo para la salud asociado con la aparición de enfermedades derivadas de agentes virales transmisibles (Gazzetta Ufficiale della Repubblica Italiana, 2020a). En este sentido, la deliberación del Consejo de Ministros estableció, a la espera de evaluación del impacto real del evento bajo revisión, la implementación de las primeras intervenciones a través de ordenanzas emitidas por el Jefe del Departamento de Protección Civil, a pesar de cualquier disposición vigente y de conformidad con los principios del sistema legal, dentro del límite de 5,000,000.00 de euros del Fondo para las Emergencias Nacionales, previsto en el decreto Legislativo del 2 de enero de 2018, relativo al Servicio Nacional de Protección Civil.

Tomando nota de la evolución de la situación epidemiológica, de la naturaleza generalizada de la epidemia, del aumento de casos así como muertes notificadas a la OMS y reconociendo que se trata de una situación de extraordinaria necesidad y urgencia, el gobierno italiano, primeramente, a través del Decreto-ley de 9 de marzo de 2020, emitió una serie de disposiciones jurídicas orientadas al fortalecimiento del Servicio Nacional de Salud para contrarrestar la emergencia epidemiológica del COVID-19 (Gazzetta Ufficiale della Repubblica Italiana, 2020b). Dichas disposiciones tuvieron como propósito establecer medidas urgentes para el acceso de personal sanitario al Servicio Nacional de Salud; reevaluar los planes de demanda del personal de salud; la contratación de médicos generales; el fortalecimiento de las redes médicas de atención; así como instaurar un esquema de incentivos para la producción de dispositivos médicos y medidas de simplificación para su compra.

Ahora bien, con el objetivo de contener los efectos negativos que se producen en el tejido socioeconómico nacional de Italia, mediante el Decreto-ley del 2 de marzo de 2020, se estableció una política de estímulo a la economía y el empleo (Gazzetta 
Ufficiale della Repubblica Italiana, 2020c), que consistió en la suspensión del pago de impuestos y contribuciones de servicios públicos, a la seguridad y la asistencia sociales; seguro obligatorio para marzo-abril de 2020; liquidación de impuestos, control, evaluación, recaudación y litigios hasta el 31 de mayo; reembolso de hipotecas (para casa de residencia) para ciudadanos con ingresos bajos/medios, así como el establecimiento de un bono de hasta 100 euros para trabajadores que laboraron en marzo de 2020, con un ingreso bruto anual de hasta 40,000 euros.

Tales medidas implicaron la adopción de una política de apoyo a empresas, empleos e ingresos, que se tradujeron en retención de empleo con apoyo de ingresos ( $80 \%$ del salario bruto y la contribución total de la seguridad social) durante los períodos de interrupción temporal o permanente de la producción como resultado de dificultades económicas, industriales o financieras.

Se extendió a todos los sectores, excepto al trabajo doméstico y a las empresas, independientemente de su tamaño, compensación salarial (600 euros/mes) a empresas no elegibles para el esquema de retención de empleo en casos de reducción de actividad o reducción de horas de trabajo; 600 euros/mes por pérdida de ingresos de trabajadores temporales, autónomos y colaboradores externos; ingresos de último recurso para apoyos para trabajadores que cesaron, redujeron o suspendieron actividades o relaciones laborales; servicios de cuidado de vales (cuidado de niños) para familias que no solicitaron un período de licencia pagado adicional; 100 euros para trabajadores en servicios esenciales; transferencia de efectivo de 300 euros por municipios para los pobres sin ingresos ni pensión; fondo Central de Garantía para apoyar la negociación de préstamos, incluso por parte de PyME; garantía del Banco Nacional de Inversiones para bancos que otorgan créditos a empresas; moratoria en el pago de préstamos por parte de las micros y PyMES, incluidas hipotecas, arrendamientos y préstamos a corto plazo; extensión del acceso al crédito por parte de microempresas a través del consorcio de garantía; mecanismos de ajuste de volatilidad para compañías de seguros, mediante un fondo de compensación de ahorro; arreglos de trabajo con modalidades simplificadas para el teletrabajo para todas las actividades y ocupaciones para las cuales es posible; procedimientos simplificados para solicitudes y notificaciones de teletrabajo; subsidios para empresas que producen dispositivos médicos y equipos de protección personal; subvenciones a empresas para la compra de equipos de protección personal y exenciones fiscales para la compra de equipos de desinfección; y, procedimientos de despido congelados hasta finales del mes de mayo para prevenir la discriminación/exclusión social.

Otras providencias urgentes adoptadas que destacan, son aquellas orientadas a contener y contrarrestar el contagio, como el confinamiento social, la restricción y prohibición de la movilidad de las personas; la suspensión de eventos y competiciones deportivas en lugares públicos o privados, y de servicios educativos de todos los niveles; condicionamiento a la apertura de lugares de culto; suspensión de las ceremonias civiles y religiosas, incluidas las funerarias; cierre de museos y lugares destinados a la cultura; limitación de las actividades comerciales de restaurantes y bares; suspensión de actividades de gimnasios, centros deportivos, piscinas, centros de natación, spas, centros culturales, centros sociales y centros de recreación. (Gazzetta Ufficiale 
della Repubblica Italiana, 2020d); así como la posibilidad de extender el estado de emergencia hasta el 31 de julio de 2020 (Gazzetta Ufficiale della Repubblica Italiana, 2020e).

\section{España}

Para hacer frente a la epidemia y con el propósito de estimular la economía y el empleo, el Gobierno de España formuló un primer paquete de disposiciones económicas orientado a reforzar el ámbito sanitario y la entrega anticipada de recursos sujetos a financiación de las comunidades autónomas, mismas que se acompañaron de medidas orientadas a la protección de las familias, el sector turismo hasta por 400 millones de euros, el aplazamiento de deudas tributarias e impuestos por un periodo de seis meses; y, la gestión eficiente de las administraciones públicas (Boletín Oficial del Estado, 2020a).

Posteriormente, de conformidad a lo dispuesto en el artículo 116.2 de la Constitución Española (Boletín Oficial del Estado, 1978) y la ley relativa a los estados de alarma, excepción y sitio (Boletín Oficial del Estado, 1981), por un lapso de quince días naturales se declaró el estado de alarma con el fin de afrontar la situación de emergencia sanitaria provocada por el coronavirus COVID-19 (Boletín Oficial del Estado, 2020b).

En este decreto, se establecieron, entre otras, medidas orientadas a limitar la libertad de circulación de las personas; realizar requisas temporales de todo tipo de bienes necesarios para el cumplimiento de los fines previstos en el real decreto, en particular para la prestación de los servicios de seguridad o de los operadores críticos y esenciales; la suspensión de la actividad educativa presencial; la suspensión de la actividad comercial, cultural, recreativa, hostelería y restauración, excluyéndose las actividades de los establecimientos comerciales minoristas de alimentación, bebidas, productos y bienes de primera necesidad, comercios farmacéuticos, sanitarios, centros o clínicas veterinarias, ópticas y productos ortopédicos, productos higiénicos, prensa y papelería, combustible para la automoción, estancos, equipos tecnológicos y de telecomunicaciones, alimentos para animales de compañía, comercio por internet, telefónico o correspondencia, tintorerías, lavanderías y el ejercicio profesional de la actividad de peluquería a domicilio. Condicionar la asistencia a los lugares de culto y a las ceremonias civiles y religiosas, incluidas las fúnebres, a la adopción de medidas organizativas consistentes en evitar aglomeraciones de personas, en función de las dimensiones y características de los lugares, de tal manera que se garantice a los asistentes la posibilidad de respetar la distancia entre ellos de al menos, un metro; medidas orientadas a reforzar el Sistema Nacional de Salud en todo el territorio nacional y el aseguramiento del suministro de bienes y servicios necesarios para la protección de la salud pública; la reducción de los servicios de transporte público; así como la garantía de suministro de energía eléctrica, productos derivados del petróleo y gas natural.

No obstante, para hacer frente al impacto económico y social del COVID-19, se establecieron medidas urgentes extraordinarias para apoyar a los trabajadores, familias 
y colectivos vulnerables; flexibilizar los mecanismos de ajuste temporal de actividad para evitar despidos; garantías de liquidez para sostener la actividad económica, así como medidas de apoyo a la investigación del COVID-19 (Boletín Oficial del Estado, 2020c). En una visión de conjunto, las medidas económicas se traducen en la movilización de hasta 200,000 millones de euros de créditos, con garantías públicas de hasta 100,000 millones y una estimación del gasto público de alrededor de 5,000 millones de euros.

Se adoptaron medidas en el ámbito laboral (Boletín Oficial del Estado, 2020d), social y económico para la protección del empleo, agilizar la tramitación y abono de prestaciones por desempleo, así como para regular un permiso retribuido recuperable para las personas trabajadoras por cuenta ajena que no presten servicios esenciales, con el fin de reducir la movilidad de la población (Boletín Oficial del Estado, 2020e) (Boletín Oficial del Estado, 2020f).

\section{Francia}

En el caso de la República Francesa, en primer lugar, se requirió la expedición de una Ley (Legifrance, 2020a), por la que, entre otros aspectos, se adicionaron diversas disposiciones al Código de Salud Pública, a fin de que se regulara el Estado de emergencia de salud, ${ }^{4}$ el cual puede declararse en todo o en parte del territorio metropolitano, así como en el territorio de las colectividades regidas por los artículos 73 y 74 de la Constitución y de Nueva Caledonia, en caso de peligro, por su naturaleza y gravedad para la salud de la población. ${ }^{5}$

En el caso específico de la epidemia por COVID-19, la ley estipulo que la duración del Estado de emergencia sanitaria será inicialmente de dos meses.

Por otra parte, la Ley de emergencia de 2020, autorizó al Gobierno para que de conformidad a las condiciones previstas en el artículo 38 de la Constitución, dentro de los tres meses posteriores a la publicación de la ley, mediante ordenanzas tome medidas para abordar las consecuencias económicas, financieras y sociales. En este sentido, las ordenanzas se han orientado a establecer previsiones que permitan al gobierno francés afrontar la epidemia en sus territorios. ${ }^{6}$

\footnotetext{
${ }^{4}$ Para efectos de su declaratoria, se precisa la emisión de un decreto del Consejo de Ministros, previo informe del Ministro de Salud. Dicho informe debe ser razonado sobre datos científicos disponibles sobre la situación de salud que motivan la decisión y circunscrito a los distritos territoriales dentro de los cuales entre en vigencia y se haga aplicable, debiendo ser informados sin demora la Asamblea Nacional y el Senado de las medidas tomadas por el Gobierno.

Por regla general, el Estado de emergencia de salud puede ser declarado hasta por un mes, sin embargo, puede ser declarado por mayor tiempo a través de una ley, previa opinión de un comité científico.

${ }^{5}$ Salvo la previsión del Estado de sitio contenido en el artículo 36, la Constitución francesa de 1958 no prevé disposiciones relativas a los estados de alarma y de excepción. Sin embargo, a través de la Loi n 55-385 du 3 avril 1955 relative à l'état d'urgence, el Estado de emergencia se activa en el caso de peligro inminente resultante de ataques serios al orden público, es decir, en el caso de eventos que presenten, por su naturaleza y su gravedad, el carácter de la calamidad pública (Legifrance, 2020b:Internet).

${ }^{6} \mathrm{~A}$ mayor abundamiento las ordenanzas pueden ser consultadas en un dossier legislativo (Legifrance, 2020c:Internet).
} 
Entre la diversidad de medidas de emergencia económica, adaptación social y laboral que en Francia se han establecido, destacan: la implementación de un plan para apoyar la economía por 45 mil millones de euros, equivalente al $2 \%$ del Producto Interno Bruto; un esquema de garantía estatal excepcional que permitirá financiar a las empresas hasta por 300 mil millones de euros. Establecimiento de un fondo de apoyo para pequeñas empresas y trabajadores independientes; aplazamiento del pago de impuestos y cotizaciones sociales para empresas; ajustes a las regulaciones a las horas de trabajo; la posibilidad de que el empleador imponga o posponga la licencia sujeta a la celebración de un acuerdo con los sindicatos a nivel de sucursal o empresa; organización de un sistema de cuidado infantil para profesionales de la salud; accionamiento del teletrabajo en todas las posiciones que lo permitan.

\section{E. Alemania}

Con el propósito de estimular la economía y el empleo, el gobierno federal alemán aprobó una serie de paquetes y garantías de apoyo social y laboral que estarán vigentes hasta finales de 2020.7 Entre ellas, destaca la extensión de líneas de crédito para las empresas a través del banco de inversión estatal federal; la protección de los alquileres, cuando los arrendatarios efectúen pagos tardíos o tengan adeudos entre el 1 de abril de 2020 y el 30 de junio de 2020, deudas que deberán pagarse hasta el 30 de junio de 2022.

En el ámbito laboral, algunas medidas implementadas son: los subsidios de trabajo a corto plazo, la indemnización total de las contribuciones de seguridad social al empleador; el establecimiento de una compensación a favor de los padres con hijos de hasta 12 años que no pueden trabajar debido al cierre de guarderías y escuelas; elegibilidad de trabajadores en sectores clave, como el de la salud o el agrícola, para la obtención de beneficios por la realización de labores a corto plazo; así como una ayuda de emergencia para trabajadores independientes y pequeñas empresas.

Finalmente, el gobierno alemán estableció una serie de medidas orientadas al otorgamiento de desgravaciones fiscales, entre las que se incluye la moratoria de deudas tributarias.

\section{F. Estados Unidos de Norteamérica}

Apoyado en lo dispuesto por la sección 319 de la Ley del Servicio de Salud Pública (Committee on Energy and Commerce U.S. House of Representatives, 2000), ${ }^{8}$ previo a consulta con los funcionarios de salud pública, el secretario del Departamento de Salud y Servicios Humanos emitió el 31 de enero de 2020, la determinación de que existe una emergencia de salud pública resultante del nuevo coronavirus (U.S. Department of Health \& Human Services, 2020a).

\footnotetext{
${ }^{7}$ El repertorio de legislación alemán para afrontar y mitigar las consecuencias de la pandemia por COVID-19, se puede consultar en la Gaceta de Leyes disponible en: https://www.bgbl.de/

${ }^{8}$ Prevé como condiciones para declarar una emergencia de salud pública que una enfermedad o trastorno la represente; o exista un brote importante de enfermedades infecciosas o ataques bioterroristas.
} 
Ante ello, el gobierno del presidente Donald J. Trump, a través de una serie de proclamaciones puso en funcionamiento políticas orientadas al cuidado de la salud frente a la transmisión del nuevo coronavirus. Así, el 31 de enero (White House, 2020a) y el 29 de febrero (White House, 2020b), emitió proclamaciones orientadas a suspender y limitar la entrada a los Estados Unidos de inmigrantes como de aquellos que no son, de todos los extranjeros que estuvieron físicamente presentes dentro de la República Popular de China -excepto las regiones administrativas especiales de Hong Kong y Macao-, así como de la República Islámica de Irán; durante el período de 14 días anteriores a su entrada o intento de entrada, instruyendo para ello al Secretario de Seguridad Nacional para que implemente todas las medidas necesarias y apropiadas para regular el viaje de personas y aeronaves a los Estados Unidos. Entre dichas medidas se ordenó el examen médico y cuando corresponda, la cuarentena de las personas que pudieron haber estado expuestas al virus.

Posteriormente, en idénticos términos, los días 11 (White House, 2020c) y 14 (White House, 2020d) de marzo emitió proclamaciones por las que, adicionalmente, ordenó suspender y limitar la entrada, de inmigrantes y no inmigrantes, de todos los extranjeros que estuvieron físicamente presentes dentro del Ârea Schengen, y el Reino Unido, excluyendo los territorios de ultramar fuera de Europa, o la República de Irlanda.

No obstante, dichas medidas restrictivas fueron endurecidas a través de la proclamación, por lo que se suspende la entrada de inmigrantes que presentan riesgos para el mercado laboral de Estados Unidos, durante la recuperación económica luego del brote por COVID-19 (White House, 2020e).

En cuanto hacer de las políticas sanitarias, debemos señalar que a través de un memorándum (White House, 2020f) se ordenó al secretario del Departamento de Salud y Servicios Humanos tomar las medidas proactivas, apropiadas y necesarias sobre la disponibilidad de respiradores de uso general, a fin de que el sistema de salud cuente con acceso a los suministros necesarios para responder a las amenazas a la salud pública. ${ }^{9}$

Ahora bien, derivado de la rápida propagación del virus por el territorio de los Estados Unidos, pero especialmente por la situación que en ese momento se afrontaba en 47 estados (1645 casos positivos), con fundamento en la Ley Nacional de Emergencias y la Ley de Seguridad Social, se declaró emergencia nacional -con efectos retroac-

\footnotetext{
${ }^{9}$ Adicionalmente, bajo el principio de coordinación entre agencias federales, estatales, locales y tribales, así como la flexibilidad en el cuidado de los ciudadanos, se ordenó ampliar la aplicación de pruebas de diagnóstico para COVID-19 aprobadas por el Estado (White House, 2020g:Internet).

Este memorándum fue reforzado a través de una orden ejecutiva por la que delegó en el secretario del Departamento de Salud y Servicios Humanos, autoridad para evitar el acaparamiento de recursos médicos y de salud necesarios para responder a la propagación de COVID-19 dentro de los Estados Unidos, incluida la autoridad para prescribir condiciones con respecto a la acumulación de dichos recursos, y para designar cualquier material como un material escaso, o como un material cuyo suministro se vería amenazado por personas que acumulan el material, ya sea en exceso de las demandas razonables de consumo comercial, personal o doméstico, o con el propósito de reventa a precios superiores a los precios vigentes en el mercado (White House, 2020h:Internet).
} 
tivos al 1 de marzo- (White House, 2020g); lo que dio pauta a que se emitiera una orden ejecutiva (White House, 2020h) por la que se delegó en el secretario del Departamento de Salud y Servicios Humanos facultades para priorizar y asignar recursos médicos y de salud para responder a la propagación de COVID-19, considerando necesaria la promoción de la defensa nacional, lo cual posibilito que los estados de California, Nueva York y Washington fueran elegibles para acceder a los beneficios del Robert $T$. Stafford Disaster Relief and Emergency Assistance Act (1988) entre los que destaca el uso de unidades de la Guardia Nacional. ${ }^{10}$

Por cuanto hace a la política económica, las acciones presidenciales inicialmente implicaron el uso del Fondo de Estabilización de Cambio en un monto total de hasta \$ 50 mil millones de dólares.

Por otra parte, el Banco de la Reserva Federal bajó las tasas de interés a cero e informo que compraría al menos 700 mil millones de dólares en valores gubernamentales y relacionados con hipotecas y anunció el establecimiento de flujos de crédito para empleadores, consumidores y empresas por un total de 300 mil millones de dólares.

Sin embargo, el surgimiento del COVID-19 implicó la emisión de un paquete económico para estimular y rescatar la economía y el empleo -el de mayores recursos que se haya aprobado en la historia de los Estados Unidos-. A través de la Coronavirus Aid, Relief, and Economic Security Act (Congress of the United States of America, 2020a) o CARES, se aprobaron asignaciones suplementarias por 2.2 billones de dólares.

Entre las medidas establecidas por la Ley CARES, destacan, proporcionar a pequeñas empresas y organizaciones, sin fines de lucro, con 500 empleados o menos, 350 mil millones de dólares en préstamos parcialmente perdonables como parte de un nuevo Programa de Protección de Cheques de Pago; expansión del programa de préstamos de emergencia por desastre de los Estados Unidos mediante el financiamiento de 10 mil millones de dólares en anticipos en solicitudes de préstamos para ayudar a las pequeñas empresas a cubrir gastos que incluyen licencia por enfermedad, nómina y alquiler; prever créditos fiscales de 5,000 dólares por salarios pagados a cada empleado por negocios afectados negativamente por el coronavirus; y, establecer un fondo de alivio que proporciona un total de 150 mil millones de dólares en apoyo fiscal federal para los gobiernos estatales y locales.

La Ley CARES, en conjunto con la Families First Coronavirus Response Act (Congress of the United States of America, 2020b) incluyen varias medidas destinadas específicamente a apoyar a los trabajadores y las empresas, incluido el pago de impuestos, tratados como un crédito fiscal reembolsable. Las parejas que ganen hasta 150,000 dólares recibirán 2,400 dólares, más 500 dólares adicionales por cada hijo. Las personas que ganen hasta 75,000 dólares recibirán 1,200 dólares, más 500 dólares adicionales por cada hijo.

\footnotetext{
${ }^{10}$ Mediante otra orden ejecutiva (White House, 2020k:Internet), a fin de proporcionar autoridad adicional a los Secretarios de Defensa y Seguridad Nacional para responder a la emergencia nacional declarada, se instruyó la preparación seleccionada de ciertos miembros de las fuerzas armadas para el servicio activo.
} 
La legislación también incluye medidas para ampliar el seguro de desempleo, que incluyen, por ejemplo: crear un nuevo programa de asistencia de desempleo pandémico (PUA, por sus siglas en inglés), para ayudar a las personas que no califican para la compensación regular por desempleo y no pueden continuar trabajando como resultado del COVID-19, como los trabajadores independientes, contratistas independientes y empleados por encargo; proporcionar, como parte de la compensación federal de desempleo pandémico (FPUC, por sus siglas en inglés), pagos adicionales de 600 dólares por semana a ciertas personas elegibles que reciben otros beneficios.

La legislación también amplía temporalmente la elegibilidad, a partir del 1 de abril, para la licencia por enfermedad remunerada, licencia familiar y médica ampliada por razones específicas relacionadas con COVID-19, así como el reembolso a los empleadores del sector privado de Estados Unidos con menos de 500 empleados con créditos fiscales por el costo de proporcionar a sus empleados vacaciones pagadas por razones específicas relacionadas con COVID-19.

Finalmente, debemos señalar que, como resultado del elevado número de contagios y muertes registrados en los Estados Unidos, el 21 de abril pasado, el secretario del Departamento de Salud y Servicios Humanos renovó, con efectos a partir del 26 de abril de 2020, la determinación de emergencia de salud pública en todo el país (U.S. Department of Health \& Human Services, 2020b).

\section{G. México}

El análisis de las medidas que se han dictado para contener y mitigar los efectos del virus SARS-CoV-2 en México, difícilmente puede ejecutarse sin que deje de pasar frente a nosotros la tentación de recurrir a la Teoría del Estado fallido, para intentar comprender la situación sanitaria, económica, social, política y jurídica que impera, puesto que dicha teoría, como concepto se refiere a una idea contemporánea que da cuenta básicamente de las problemáticas, deficiencias e imposibilidad de ciertos Estados para responder a las diversas demandas que hacen sus ciudadanos (Zapata; 2014:91).

No es nuestra intención abonar a dicha teoría, mucho menos debatir, si México es un Estado fallido, si para ello el eventual análisis que pueda realizarse sobre la base del discurso político en torno al COVID-19, ello desviaría nuestros propósitos. Afortunadamente, para lo que aquí venimos planteando es consignar que, ante una problemática de la magnitud que atravesamos, las medidas emprendidas, desde un punto de vista estrictamente jurídico, pueden calificarse como insuficientes para que el estado mexicano responda adecuadamente a las diversas demandas que ha traído consigo la epidemia.

Pese a una inicial postura política de minimizar el riesgo de contagios por el nuevo coronavirus el 23 de marzo de 2020, el Consejo de Salubridad General reconoció la enfermedad que genera el virus SARS-CoV2 como grave de atención prioritaria (Diario Oficial de la Federación, 2020a), por lo que ordenó establecer una serie de acti- 
vidades de preparación y respuesta (Diario Oficial de la Federación, 2020b). ${ }^{11}$

En el ámbito de la salubridad general, con el propósito de combatir la enfermedad, se establecieron una serie de acciones extraordinarias consistentes en la utilización de elementos auxiliares, todos los recursos médicos y de asistencia social de los sectores público, social y privado existentes en las regiones afectadas del territorio nacional; la adquisición de todo tipo de bienes y servicios, a nivel nacional o internacional, relacionados con equipo médico, agentes de diagnóstico, material quirúrgico y de curación y productos higiénicos, así como todo tipo de mercancías y objetos que resulten necesarios para hacer frente a la contingencia, sin obligación de llevar a cabo el procedimiento de licitación pública, por las cantidades o conceptos necesarios para afrontarla; la importación, así como la adquisición en el territorio nacional de los bienes y servicios referidos, sin necesidad de agotar trámite administrativo alguno, por las cantidades o conceptos requeridos para afrontar la contingencia; y, llevar a cabo las medidas pertinentes para evitar la especulación de precios y el acopio de insumos esenciales de los bienes y servicios clínicos y médicos citados (Diario Oficial de la Federación, 2020c):;2 la prohibición de incinerar los cuerpos no identificados e identificados no reclamados, fallecidos a consecuencia de la enfermedad por el virus SARS-CoV2 (Diario Oficial de la Federación, 2020e), así como la supresión de un requisito de habilitación clínica para la prestación de servicios médicos hospitalarios y de hemodiálisis privados (Diario Oficial de la Federación, 2020f).

Ahora bien, desde una perspectiva estrictamente constitucional y reglamentaria, el 30 de marzo de 2020, el Consejo de Salubridad General declaró a la enfermedad generada por el virus SARS-CoV2 como emergencia sanitaria por causa de fuerza mayor (Diario Oficial de la Federación, 2020g), acción que condujo a que en los sectores público, social y privado se implementaran medidas de suspensión de actividades no esenciales durante el periodo comprendido del 30 de marzo al 30 de abril de 2020 (Diario Oficial de la Federación, 2020h), ${ }^{13}$ el resguardo domiciliario, y las relativas al cuidado de la salud y el fomento de la higiene personal (Diario Oficial de la Federación, 2020i).

Por cuanto hace a las medidas de estímulo a la economía y el empleo, debemos señalar que el gobierno federal únicamente ha establecido providencias para la

\footnotetext{
${ }^{11}$ Entre otros aspectos, las medidas consisten la suspensión temporal de las actividades escolares, hasta el 17 de abril de 2020; la suspensión temporal de las actividades de los sectores público, social y privado que involucren la concentración física, tránsito o desplazamiento de personas, hasta el 19 de abril del 2020; la suspensión temporal y hasta nuevo aviso, los eventos masivos y las reuniones y congregaciones de más de 100 personas; así como el cumplimiento de las medidas básicas de higiene (Diario Oficial de la Federación, 2020b:Internet).

${ }^{12} \mathrm{~A}$ fin de contar con los recursos materiales y humanos para prestar a la población los servicios de salud que otorga el Estado, la simplificación de los procedimientos de adquisición y la autorización de pagos anticipados a proveedores fue normado a través de un acuerdo diverso (Diario Oficial de la Federación, 2020d:Internet).

${ }^{13}$ Con el objeto de asegurar la adecuada implementación y cumplimiento de las medidas de seguridad sanitaria y, derivado del análisis técnico realizado por el Grupo Científico Asesor del Consejo de Salubridad General, la suspensión de actividades no esenciales originalmente planteada se amplió hasta el 30 de mayo de 2020 .
} 
HiRAM RaÚl PiÑa Libien / http://orcid.org/0000-0002-5745-6880. / Correo electrónico: hrpl@hotmail.com ENRIQUE URIBE ARZATE / https://orcid.org/0000-0003-2381-232X. / Correo electrónico: vercingtx@hotmail.com Jorge Olvera GARCía / https://orcid.org/0000-0002-2607-8987. / Correo electrónico: jorgeolvera62@hotmail.com

fijación de tarifas de energía eléctrica (Diario Oficial de la Federación, 2020j); férreas restricciones al gasto gubernamental (Diario Oficial de la Federación, 2020k); un programa de apoyo financiero a microempresas familiares (Diario Oficial de la Federación, 2020l); así como la puesta en práctica de medidas preventivas para evitar la asistencia a centros de trabajo y permisos con goce de sueldo a favor de los trabajadores.

\section{LA ORGANIZACIÓN DE LAS NACIONES UNIDAS Y LA COMISIÓN INTERAMERICANA DE DERECHOS HUMANOS ANTE LA PANDEMIA}

El Informe anual sobre preparación mundial para las emergencias sanitarias, elaborado por la Junta de Vigilancia Mundial de la Preparación (2019), advirtió que el mundo no está preparado para enfrentar la amenaza de una pandemia fulminante provocada por un patógeno respiratorio, que podría matar entre 50 a 80 millones de personas y liquidar casi el 5\% de la economía mundial, ya que, una pandemia de esa escala sería una catástrofe que desencadenaría caos, inestabilidad e inseguridad generalizadas (6).

Para el ámbito de lo estatal, ha sido un infortunio que no se le diera seriedad a tal advertencia, que lo sentenciado en dicho informe hoy sea una realidad. Lo anterior explica en gran medida el colapso sufrido en diversos sistemas de salud (Estados Unidos, España, Italia y Ecuador), denota que esos y otros gobiernos no realizaron previsiones para evitar una pandemia como la generada por el virus SARS-CoV-2, a pesar que los Jefes de Estado y de Gobierno se comprometieron a promover sistemas de salud sólidos y resilientes, igual que aplicar correctamente el Reglamento Sanitario Internacional (2005) y asegurar la preparación para pandemias y la prevención, detección y respuesta en caso de que se produzca algún brote. (Organización de las Naciones Unidas, 2019).

Esta cruda realidad condujo a que la Asamblea General de la ONU realizara un llamado a la solidaridad mundial para luchar contra la enfermedad por coronavirus de 2019 (Organización de las Naciones Unidas, 2020a). En dicho instrumento, además de reconocer los efectos disruptivos de la pandemia en los ámbitos social y económico, instó a los estados a brindarse cooperación internacional y apoyarse en el multilateralismo para intercambiarse información, conocimientos científicos y mejores prácticas conforme a las directrices recomendadas por la OMS, a la vez que puso de relieve la necesidad de que respeten plenamente los derechos humanos ante la crisis global generada por el nuevo coronavirus. En relación con este posicionamiento, la Asamblea General realizó un exhorto a la cooperación internacional para garantizar el acceso mundial a los medicamentos, las vacunas y el equipo médico con los que hacer frente a la COVID-19 (Organización de las Naciones Unidas, 2020b).

$\mathrm{Al}$ observar que diversos instrumentos constitucionales amparados en el ejercicio del Derecho de excepción suspendían y restringían derechos y libertades 
fundamentales en las Américas, la Comisión Interamericana de Derechos Humanos (CIDH), emitió una serie de estándares y recomendaciones orientadas a que en el contexto de la pandemia, los Estados guíen su actuación conforme a su obligación de respetar y garantizar los derechos humanos, así como por los principios, compromisos y normas de derecho internacional aplicables (Comisión Interamericana de Derechos Humanos, 2020).

La pretensión de la CIDH es incidir en el actuar de los Estados para que, en toda estrategia, política o medida estatal, además de adoptar un enfoque de derechos humanos, garanticen, protejan y aseguren los derechos económicos, sociales, culturales y ambientales de todas las personas, especialmente los derechos de los grupos en situación de vulnerabilidad, personas mayores, aquellas privadas de su libertad, mujeres, pueblos indígenas, migrantes, solicitantes de asilo, refugiados, apátridas, víctimas de trata de personas y desplazados internos, niños, niñas y adolescentes, personas LGBTI, afrodescendientes y con discapacidad, constituyendo un esfuerzo para evitar la instauración de dictaduras democráticas en las Américas.

\section{REFLEXIONES FINALES}

La pandemia provocada por el virus SARS-CoV-2 no solamente ha conducido a infaustas consecuencias en los sistemas sanitarios, económicos, sociales, políticos y jurídicos a nivel planetario, acrecentó las asimetrías y agudizó la crisis de derechos humanos en todos los países, nos ha colocado frente al abismo de una crisis global humanitaria.

El paradigma constitucional nacional en que se sustentan los países abordados en el presente trabajo denota que, las políticas de prevención, contención y mitigación han fungido como mecanismo de atención para prevenir el riesgo de contagio de la enfermedad COVID-19, pero en realidad han sido una respuesta incompatible con las necesidades y demandas de las personas, así como de la vigencia de los derechos humanos. Ello es atribuible en gran medida a la subordinación económica, pero también, a la descoordinación internacional y la ausencia de protocolos jurídicos de actuación del Estado constitucional.

No menos importante es señalar que también cobran relevancia las posturas políticas empeñadas en desestimar los efectos adversos del coronavirus a la salud, lo que ha conducido a la politización de la emergencia sanitaria, pues el SARS-CoV-2 no aporta una renta electoral ni genera popularidad democrática, por el contario ha ensanchado la crisis de legitimidad y representación política.

Tras lo expuesto en el presente trabajo, queda evidenciado que las instituciones de garantía de los derechos humanos -tanto a nivel internacional como regional-, frente a las consecuencias y efectos de la pandemia han desarrollado un papel ornamental ante las unilaterales respuestas de los estados constitucionales, pues 
la imposición de estados de alarma, emergencia sanitaria o cualquier otro, no solamente han restringido los derechos y libertades fundamentales de las personas, también han arriesgado la vida y el actuar democrático.

Coincidimos con la crítica que efectúa el Constitucionalismo más allá del Estado de Luigi Ferrajoli, pero diferimos en su pretensión de que una de las innovaciones de las garantías institucionales, de los derechos fundamentales, se limite a la introducción de técnicas y funciones adecuadas en los organismos internacionales o regionales y reducirlo a su financiación. Una situación extraordinaria, como es la calamidad experimentada por el virus SARS-CoV-2, demanda que asuman un rol activo mediante la implementación de políticas globales de acceso abierto a la información que generen los sistemas de salud a nivel mundial, el acceso gratuito a pruebas o test de diagnóstico sin restricciones; así como ejercer un control centralizado de la información epidemiológica que sobre la base de datos científicos, permita a los gobiernos determinar adecuadamente el levantamiento de las restricciones impuestas; consideramos que sobre estos elementos podrían materializarse las garantías del constitucionalismo de los bienes primordiales.

La pandemia nos ha confrontado a una nueva realidad, ha desnudado una vez más la fragilidad del ser humano, pero también, nos ha reafirmado que a los poderes económicos mundiales y políticos nacionales poco les interesa el riesgo de contagio de las personas, la discriminación y la exclusión, esos poderes, nos han mostrado que la reapertura de la economía global y la competencia electoral interna son sus prioridades, por lo que, la construcción de un constitucionalismo de derecho internacional o supranacional y la introducción de una constitucionalidad regida por el derecho privado, en efecto, son utopías por las cuales habrá que insistir y luchar.

Finalmente, debemos señalar que es preciso tomar en serio la propuesta teórica que realiza el Constitucionalismo más allá del Estado, sin perder de vista la urgente necesidad de reducir los impactos negativos de las medidas estatales de restricción a los derechos y libertades fundamentales, pues el escenario experimentada durante la pandemia COVID-19 ha colocado a la vida democracia en una situación de riesgo inminente que amenaza tornarse en comunismos locales y regionales.

\section{REFERENCIAS}

1. Boletín Oficial del Estado. (29 de diciembre de 1978). Constitución Española. Madrid, España. Recuperado de https://www.boe.es/buscar/pdf/1978/BOE-A-1978-31229-consolidado.pdf.

2. Boletín Oficial del Estado. (1 de junio de 1981). Ley Orgánica 4/1981. Madrid, España. Recuperado de https://www.boe.es/buscar/pdf/1981/BOE-A-1981-12774-consolidado.pdf. 
3. Boletín Oficial del Estado. (12 de marzo de 2020a). Real Decreto Ley 7/2020. Madrid, España. Recuperado de https://www.boe.es/buscar/pdf/2020/BOE-A-2020-3580-consolidado.pdf.

4. Boletín Oficial del Estado. (14 de marzo de 2020b). Real Decreto 463/2020, Madrid, España. Recuperado de https://www.boe.es/buscar/pdf/2020/BOE-A-2020-3692-consolidado.pdf.

5. Boletín Oficial del Estado. (17 de marzo de 2020c). Real Decreto Ley 8/2020. Madrid, España. Recuperado de https://www.boe.es/buscar/pdf/2020/BOE-A-2020-3824-consolidado.pdf.

6. Boletín Oficial del Estado. (27 de marzo 2020d). Real Decreto Ley 9/2020. Madrid, España. Recuperado de https://www.boe.es/boe/dias/2020/03/28/pdfs/BOE-A-20204152.pdf.

7. Boletín Oficial del Estado. (29 de marzo de 2020e). Real Decreto Ley 10/2020. Madrid, España. Recuperado de https://www.boe.es/boe/dias/2020/03/29/pdfs/BOE-A-2020-41 66.pdf.

8. Boletín Oficial del Estado. (31 de marzo de 2020f). Real Decreto Ley 11/2020, Madrid. Recuperado de https://www.boe.es/boe/dias/2020/04/01/pdfs/BOE-A-2020-4208.pdf.

9. China Banking and Insurance Regulatory Comission. (2020). 银保监会 人民银行 发 展改革委工业和信息化部财政部关于对中小微企业

贷款实施临时性延期还本付息的通知. Recuperado de http://www.cbirc.gov.cn/cn/view /pages/ItemDetail.html?docId=892278\&itemId=926.

10. Committee on Energy and Commerce U.S. House of Representatives. (2020). Public Health Services Act, Washington, D.C., Estados Unidos, 31 de diciembre de 2000. Recuperado de https://web.archive.org/web/20090823185830/http://energycommerce. house. gov/images/stories/Documents/PDF/publications/109_health.pdf.

11. Comisión Interamericana de Derechos Humanos. (10 de abril de 2020). Pandemia y Derechos Humanos en las Américas, Resolución No. 1/2020, Washington, D.C., Estados Unidos. Recuperado de https://www.oas.org/es/cidh/decisiones/pdf/Resolucion-1-20es.pdf.

12. Congress of the United States of America. (27 de marzo de 2020a). Coronavirus Aid, Relief, and Economic Security Act, Washington, D.C., Estados Unidos. Recuperado de https://www.congress.gov/116/bills/hr748/BILLS-116hr748enr.pdf.

13. Congress of the United States of America. (18 de marzo de 2020b). Families First Coronavirus Response Act. Washington, D.C., Estados Unidos. Recuperado de https://www.congress.gov/116/plaws/publ127/PLAW-116publ127.pdf. 
Hiram RaÚl Pĩ̃a Libien / http://orcid.org/0000-0002-5745-6880. / Correo electrónico: hrpl@hotmail.com ENRIQUE URIBE ARZATE / https://orcid.org/0000-0003-2381-232X. / Correo electrónico: vercingtx@hotmail.com Jorge Olvera García / https://orcid.org/0000-0002-2607-8987. / Correo electrónico: jorgeolvera62@hotmail.com

14. Diario Oficial de la Federación. (23 de marzo de 2020). Acuerdo por el que el Consejo de Salubridad General reconoce la epidemia de enfermedad por el virus SARS-CoV2 (COVID-19) en México, como una enfermedad grave de atención prioritaria, así como se establecen las actividades de preparación y respuesta ante dicha epidemia. Recuperado de http://dof.gob.mx/nota_detalle.php?codigo=5590161\&fecha=23/03/2020.

15. Diario Oficial de la Federación. (24 de marzo de 2020b). Acuerdo por el que se establecen las medidas preventivas que se deberán implementar para la mitigación y control de los riesgos para la salud que implica la enfermedad por el virus SARS-CoV2 (COVID-19). Recuperado de http://dof.gob.mx/nota_detalle.php?codigo=5590339\&fe cha $=24 / 03 / 2020$.

16. Diario Oficial de la Federación. (27 de marzo de 2020c). Decreto por el que se declaran acciones extraordinarias en las regiones afectadas de todo el territorio nacional en materia de salubridad general para combatir la enfermedad grave de atención prioritaria generada por el virus SARS-CoV2 (COVID-19). Recuperado de http://dof.gob.mx/nota_detalle. php?codigo $=5590673 \&$ fecha $=27 / 03 / 2020$.

17. Diario Oficial de la Federación. (2020d). Acuerdo por el que se establecen acciones extraordinarias que se deberán de realizar para la adquisición e importación de los bienes y servicios a que se refieren las fracciones II y III del artículo Segundo del Decreto por el que se declaran acciones extraordinarias en las regiones afectadas de todo el territorio nacional en materia de salubridad general para combatir la enfermedad grave de atención prioritaria generada por el virus SARS-CoV2 (COVID-19), publicado el 27 de marzo de 2020, 3 de abril de 2020. Recuperado de http://dof.gob.mx/nota_detalle.php?codigo=5591156\&fecha $=03 / 04 / 2020$.

18. Diario Oficial de la Federación. (2020e). Acuerdo por el que se prohíbe la incineración de cuerpos no identificados e identificados no reclamados fallecidos a consecuencia de la enfermedad por el virus SARS-CoV2 (COVID-19) y se sugieren medidas para el registro de las defunciones en el marco de la emergencia sanitaria, 17 de abril de 2020. Recuperado de http://dof.gob.mx/nota_detalle.php?codigo=5591880\&fecha=17/04/2020.

19. Diario Oficial de la Federación. (2020f). Acuerdo por el que se adiciona un artículo Noveno al similar por el que se establece como obligatorio, a partir del 1 de enero de 2012, el requisito de certificación del Consejo de Salubridad General a los servicios médicos hospitalarios y de hemodiálisis privados, que celebren contratos de prestación de servicios con las dependencias y entidades de las administraciones públicas de los gobiernos federal, estatales, del Distrito Federal y municipales, publicado el 29 de diciembre de 2011, 22 de abril de 2020. Recuperado de http://dof.gob.mx/nota_detalle.php?codigo= 5592107 \&fecha $=22 / 04 / 2020$.

20. Diario Oficial de la Federación. (30 de marzo de 2020g). Acuerdo por el que se declara como emergencia sanitaria por causa de fuerza mayor, a la epidemia de enfermedad generada por el virus SARS-CoV2 (COVID-19). Recuperado de http://dof.gob.mx/nota_detalle.php?codigo $=5590745 \&$ fecha $=30 / 03 / 2020$. 
21. Diario Oficial de la Federación. (2020h). Acuerdo por el que se modifica el similar por el que se establecen acciones extraordinarias para atender la emergencia sanitaria generada por el virus SARS-CoV2, publicado el 31 de marzo de 2020, 21 de abril de 2020. Recuperado de http://dof.gob.mx/nota_detalle.php?codigo=5592067\&fecha=21/04/2020.

22. Diario Oficial de la Federación. (31 de marzo de 2020i). Acuerdo por el que se establecen acciones extraordinarias para atender la emergencia sanitaria generada por el virus SARS-CoV2. Recuperado de http://dof.gob.mx/nota_detalle.php?codigo= 5590914 \&fecha $=31 / 03 / 2020$.

23. Diario Oficial de la Federación. (17 de abril de 2020j). Acuerdo por el que se determina el mecanismo de fijación de tarifas finales de energía eléctrica del suministro básico a usuarios domésticos, por el periodo que se indica, con motivo de la emergencia sanitaria por causa de fuerza mayor derivada de la epidemia de enfermedad generada por el virus SARS-CoV2 (COVID-19). Recuperado de http://dof.gob.mx/nota_detalle.php?codigo=55 91868\&fecha $=17 / 04 / 2020$.

24. Diario Oficial de la Federación. (23 de abril de 2020k). Decreto por el que se establecen las medidas de austeridad que deberán observar las dependencias y entidades de la Administración Pública Federal bajo los criterios que en el mismo se indican. Recuperado de http://dof.gob.mx/nota_detalle.php?codigo $=5592205 \&$ fecha $=23 / 04 / 2020$.

25. Diario Oficial de la Federación. (24 de abril de 2020l). Lineamientos para la Operación del Programa de Apoyo Financiero a Microempresas Familiares. Recuperado de http://dof.gob.mx/nota_detalle.php?codigo=5592265\&fecha=24/04/2020.

26. Ferrajoli, Luigi. (2018). Constitucionalismo más allá del Estado. Traducción de Perfecto Andrés Ibáñez, Totta, Madrid.

27. Gazzetta Ufficiale della Repubblica Italiana. (2020a). Anno $161^{\circ}$ - Numero 26, Parte Prima, Roma - Sabato, $1^{\circ}$ febbraio 2020, http://www.gazzettaufficiale.it/eli/gu/2020 /02/01/26/sg/pdf.

28. Gazzetta Ufficiale della Repubblica Italiana. (2020b). Anno $161^{\circ}$ - Numero 62, Parte Prima, Roma - Lunedì, 9 marzo 2020, https://www.gazzettaufficiale.it/eli/gu/2020/ 03/09/62/sg/pdf.

29. Gazzetta Ufficiale della Repubblica Italiana. (2020c). Anno $161^{\circ}$ - Numero 53, Parte Prima, Roma - Lunedì, 2 marzo 2020, https://www.gazzettaufficiale.it/eli/gu/2020/ 03/02/53/sg/pdf.

30. Gazzetta Ufficiale della Repubblica Italiana. (2020d). Anno $161^{\circ}$ - Numero 59, Parte Prima, Roma - Domenica, 8 marzo 2020, https://www.gazzettaufficiale.it/eli/gu/2020/ 03/08/59/sg/pdf.

31. Gazzetta Ufficiale della Repubblica Italiana. (2020e). Anno 161 - Numero 79, Parte Prima, Roma - Mercoledì, 25 marzo 2020, https://www.gazzettaufficiale.it/eli/gu/2020 /03/25/79/sg/pdf. 
Hiram RaÚl PiÑa Libien / http://orcid.org/0000-0002-5745-6880. / Correo electrónico: hrpl@hotmail.com ENRIQUE URIBE ARZATE / https://orcid.org/0000-0003-2381-232X. / Correo electrónico: vercingtx@hotmail.com Jorge Olvera GARCía / https://orcid.org/0000-0002-2607-8987. / Correo electrónico: jorgeolvera62@hotmail.com

32. Gobierno Popular Central de la República Popular de China. (2020a). 关于进一步强 化金融支持防控新型冠状病毒感染肺炎疫情的通知. Recuperado de http://www.gov.cn/zhengce/zhengceku/2020-02/01/content_5473639.htm.

33. Gobierno Popular Central de la República Popular de China. (2020b). 关于支持金融 强化服务 做好新型冠状病毒感染肺炎疫情防控工作的通知. Recuperado de http://www.gov.cn/zhengce/zhengceku/2020-02/03/content_5474105.htm.

34. Gobierno Popular Central de la República Popular de China. (2020c). 中国银保监会 办公厅关于进一步做好疫情防控金融服务的通知. Recuperado de http://www.gov.cn/ zhengce/zhengceku/2020-02/16/content_5479561.htm.

35. Gobierno Popular Central de la República Popular de China. (2020d). 国家医保局 财 政部 税务总局关于阶段性减征 职工基本医疗保险费的指导意见. Recuperado dehttp:// www.gov.cn/zhengce/zhengceku/2020-02/23/content_5482279.htm

36. Gobierno Popular Central de la República Popular de China. (2020e). 国务院办公厅 关于应对新冠肺炎疫情影响 强化稳就业举措的实施意见. Recuperado de http://www. gov.cn/zhengce/content/2020-03/20/content_5493574.htm

37. Homeland Security Digital Library (23 de noviembre de 1988). Robert T. Stafford Disaster Relief and Emergency Assistance Act, Washington, D.C., Estados Unidos. Recuperado de https://www.hsdl.org/?view\&did=806354.

38. Johns Hopkins University. (2020). Coronavirus Resource Center. Recuperado de https://coronavirus.jhu.edu/.

39. Junta de Vigilancia Mundial de la Preparación. (2019). Un mundo en peligro: informe anual sobre preparación mundial para las emergencias sanitarias. Ginebra, Organización Mundial de la Salud.

40. Legifrance. (2020a). Loi n 2020-290 d'urgence pour faire face à l'épidémie de covid-19, Paris, 23 de marzo de 2020, Francia. Recuperado de https://www.legifrance.gouv.fr/affichTexte.do?cidTexte=JORFTEXT000041746313\&categorieLien=i.

41. Legifrance. (3 de abril de 2020b). Loi n 55-385 relative à l'état d'urgence, Paris, Francia. Recuperado de https://www.legifrance.gouv.fr/affichTexte.do?cidTexte=JORFTE XT000000695350.

42. Legifrance. (2020c). Dossiers législatifs - Ordonnances de la XVème législature, Paris, Francia, 2020. Recuperado de https://www.legifrance.gouv.fr/affichOrdonnance. do? annee $=2020 \&$ legislature $=15$.

43. Ministry of Human Resources and Social Security of the People's Republic of China. (2020). 人社部公布失业保险稳岗返还网上申领平台. Recuperado de http://www.mohrss.gov.cn/SYrlzyhshbzb/shehuibaozhang/gzdt/202002/t20200212_359661.ht ml. 
44. M. Palacios Cruz, E. Santos, M.A. Velázquez Cervantes, M. León Juárez. (2020). COVID-19, una emergencia de salud pública mundial. Revista Clínica Española, https://doi.org/10.1016/j.rce.2020.03.001.

45. Ministry of Human Resources and Social Security of the People's Republic of China. (2020b). 人力资源社会保障部财政部国家卫生健康委关于因履行工作职责感染 新型冠状病毒肺炎的医护及相关工作人员有关保障问题的通知. Recuperado de http:// www.mohrss.gov.cn/gkml/zcfg/gfxwj/202001/t20200123_357525.html.

46. Ministry of Human Resources and Social Security of the People's Republic of China. (2020c). 人力资源社会保障部 财政部税务总局关于阶段性减免企业社会保险费 的通知. Recuperado de http://www.mohrss.gov.cn/gkml/zcfg/gfxwj/202002/t20200 221_360350.html.

47. Ministry of Human Resources and Social Security of the People's Republic of China. (2020d). 人力资源社会保障部 全国总工会 中国企业联合会/中国企业家协会 全 国工商联 关于做好新型冠状病毒感染肺炎疫情防控期间稳定劳动关系支持企业复工复 产的意见. Recuperado de http://www.mohrss.gov.cn/gkml/zcfg/gfxwj/202002/t20200 207_358328.html

48. National Healthcare Security Administration. (2020). 国家医保局 国家卫生健康委 关于推进新冠肺炎疫情防控期间开展“互联网+”医保服务的指导意见. Recuperado de http://www.nhsa.gov.cn/art/2020/3/2/art_37_2750.html.

49. Organización de las Naciones Unidas. (2019). Declaración política de la reunión de alto nivel sobre la cobertura sanitaria universal "Cobertura sanitaria universal: avanzando juntos para construir un mundo más saludable", Resolución A/RES/74/2, 18 de octubre de 2019. Recuperado de https://undocs.org/es/A/RES/74/2.

50. Organización de las Naciones Unidas. (2020a). Solidaridad mundial para luchar contra la enfermedad por coronavirus de 2019 (COVID-19), Resolución A/RES/74/270, 3 de abril de 2020. Recuperado de https://undocs.org/es/A/RES/74/270.

51. Organización de las Naciones Unidas. (2020b). Cooperación internacional para garantizar el acceso mundial a los medicamentos, las vacunas y el equipo médico con los que hacer frente a la COVID-19, Resolución A/RES/74/274, 21 de abril de 2020. Recuperado de https://undocs.org/es/A/RES/74/274.

52. Radio Radicale. (2020). Un Pensiero, una Costituzione, una Politica - Inaugurazione della Scuola "Costituente Terra". Recuperado de https://www.radioradicale.it/scheda/ 598888/un-pensiero-una-costituzione-una-politica-inaugurazione-della-scuola-costi tuente-terra.

53. Ruelas Barajas, Enrique y Alonso Concheiro, Antonio. (2010). Los futuros de la salud en México 2050, México, Consejo de Salubridad General. 
HiRAM RAÚl PiÑa Libien / http://orcid.org/0000-0002-5745-6880. / Correo electrónico: hrpl@hotmail.com EnRIQUe URIBE ARZATE / https://orcid.org/0000-0003-2381-232X. / Correo electrónico: vercingtx@hotmail.com JORGE Olvera GaRCía / https://orcid.org/0000-0002-2607-8987. / Correo electrónico: jorgeolvera62@hotmail.com

54. State Taxation Administration. (2020). 关于支持新型冠状病毒感染的肺炎疫情防控 有关税收征收管理事项的公告. Recuperado de http://www.chinatax.gov.cn/chinatax/n810341/n810755/c5143593/content.html.

55. The State Council. (2020a). State Council executive meeting on Feb 5. Recuperado de http://english.www.gov.cn/policies/infographics/202002/06/content_WS5e3 bb825c6 d0a585c76ca932.html.

56. The State Council. (2020b). China to introduce strong financial measures to help smaller firms tide over difficulties. Recuperado de http://english.www.gov.cn/premier/news /202002/25/content_WS5e5534dac6d0c201c2cbce84.html.

57. The State Council. (2020c). Quick view: State Council executive meeting on March 3. Recuperado de http://english.www.gov.cn/policies/infographics/202003/04/content_ WS5e5f45b7c6d0c201c2cbd84b.html.

58. The State Council. (2020c). Quick view: State Council executive meeting on March 10. Recuperado de http://english.www.gov.cn/policies/infographics/202003/12/content WS5e69d419c6d0c201c2cbe1ec.html.

59. The State Council. (2020e). Quick view: State Council executive meeting on March 17. Recuperado de http://english.www.gov.cn/policies/infographics/202003/18/content WS5e71e065c6d0c201c2cbe9bf.html.

60. U.S. Department of Health \& Human Services. (2020a). Determination that a Public Health Emergency Exists, Washington, D.C., Estados Unidos, 31 de enero de 2020. Recuperado de https://www.phe.gov/emergency/news/healthactions/phe/Pages/2019-nCo V.aspx.

61. U.S. Department of Health \& Human Services. (2020b). Renewal of Determination That A Public Health Emergency Exists, Washington, D.C., Estados Unidos, 21 de abril de 2020. Recuperado de https://www.phe.gov/emergency/news/healthactions/phe/Pages/covid19-21apr2020.aspx.

62. White House. (2020a), Proclamation on Suspension of Entry as Immigrants and Nonimmigrants of Persons who Pose a Risk of Transmitting 2019 Novel Coronavirus, Washington, D.C., Estados Unidos, 31 de enero de 2020. Recuperado de https://www.whitehouse.gov/presidential-actions/proclamation-suspension-entry-immigrants-nonim migrants-persons-pose-risk-transmitting-2019-novel-coronavirus/.

63. White House. (2020b). Proclamation on the Suspension of Entry as Immigrants and Nonimmigrants of Certain Additional Persons Who Pose a Risk of Transmitting Coronavirus, Washington, D.C., Estados Unidos, 29 de febrero de 2020. Recuperado de https://www.whitehouse.gov/presidential-actions/proclamation-suspension-entry- immigrants -nonimmigrants-certain-additional-per sons-pose-risk-transmitting-coronavirus/. 
64. White House. (2020c). Proclamation-Suspension of Entry as Immigrants and Nonimmigrants of Certain Additional Persons Who Pose a Risk of Transmitting 2019 Novel Coronavirus, Washington, D.C., Estados Unidos, 11 de marzo de 2020. Recuperado de https://www.whitehouse.gov/presidential-actions/proclamation-suspension -entry-immigrants-nonimmigrants-certain-additional-persons-pose-risk-transmi tting-2019-novel-coronavirus/.

65. White House. (2020d). Proclamation on the Suspension of Entry as Immigrants and Nonimmigrants of Certain Additional Persons Who Pose a Risk of Transmitting Coronavirus, Washington, D.C., Estados Unidos, 14 de marzo de 2020. Recuperado de https://www.whitehouse.gov/presidential-actions/proclamation-suspension-entry-immigrants -nonimmigrants-certain-additional-persons-pose-risk-transmitting-coronavirus-2/.

66. White House. (22 de abril de 2020e). Proclamation Suspending Entry of Immigrants Who Present Risk to the U.S. Labor Market During the Economic Recovery Following the COVID-19 Outbreak. Washington, D.C., Estados Unidos. Recuperado de https://www.whitehouse.gov/presidential-actions/proclamation-suspending-entry-immigrants -present-risk-u-s-labor-market-economic-recovery-following-covid-19-outbreak/.

67. White House. (11 de marzo de 2020f). Memorandum on Expanding State-Approved Diagnostic Tests. Washington, D.C., Estados Unidos. Recuperado de https://www.whitehouse.gov/presidential-actions/memorandum-expanding-state-approved-diagnostic -tests/.

68. White House. (13 de marzo de 2020g). Memorandum on Expanding State-Approved Diagnostic Tests, Washington, D.C., Estados Unidos. Recuperado de https://www.whitehouse.gov/presidential-actions/memorandum-expanding-state-approved-diagnostic -tests/.

69. White House. (23 de marzo de 2020h). Executive Order on Preventing Hoarding of Health and Medical Resources to Respond to the Spread of COVID-19. Washington, D.C., Estados Unidos. Recuperado de https://www.whitehouse.gov/presidential-actions/executive-order-preventing-hoarding-health-medical-resources-respond-spreadcovid-19/.

70. White House. (13 de marzo de 2020i). Proclamation on Declaring a National Emergency Concerning the Novel Coronavirus Disease (COVID-19) Outbreak, Washington, D.C., Estados Unidos. Recuperado de https://www.whitehouse.gov/presidential-actions /proclamation-declaring-national-emergency-concerning-novel-coronavirus-disease -covid-19-outbreak/.

71. White House. (2020j) Memorandum on Providing Federal Support for Governors' Use of the National Guard to Respond to COVID-19, Washington, D.C., Estados Unidos, 18 de marzo de 2020. Recuperado de https://www.whitehouse.gov/presidential-actions/me morandum-providing-federal-support-governors-use-national-guard- respond-covid-19/. 
Hiram RaÚl PiÑa Libien / http://orcid.org/0000-0002-5745-6880. / Correo electrónico: hrpl@hotmail.com ENRIQUE URIBE ARZATE / https://orcid.org/0000-0003-2381-232X. / Correo electrónico: vercingtx@hotmail.com Jorge Olvera GARCía / https://orcid.org/0000-0002-2607-8987. / Correo electrónico: jorgeolvera62@hotmail.com

72. White House. (2020k). EO to Order the Selected Reserve and Certain Members of the Individual Ready Reserve of the Armed Forces to Active Duty, Washington, D.C., Estados Unidos, 27 de marzo de 2020. Recuperado de https://www.whitehouse.gov/presidential-actions/eo-order-selected-reserve-certain-members-individual-ready -reserve-armed-forces-active-duty/.

73. White House. (20 de marzo de 2020l). Memorandum on the Delegation of Functions Under 31 U.S.C. 5302, Washington, D.C., Estados Unidos. Recuperado de https://www.whitehouse.gov/presidential-actions/memorandum-delegation-functions-31-u-s-c5302/.

74. Zapata Callejas, J. S. (2014). La teoría del estado fallido: entre aproximaciones y disensos. Revista Relaciones Internacionales, Estrategia y Seguridad, 9(1), 87-110. Recuperado de https://doi.org/10.18359/ries.52. 